\title{
Characteristics of the Bed of the Lower Columbia Glacier, Alaska
}

\author{
NEIL HUMPHREY \\ Department of Geology and Geophysics, University of Wyoming, Laramie

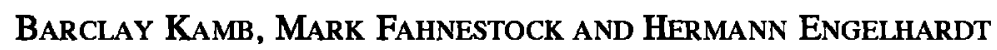 \\ Division of Geological and Planetary Sciences, California Institute of Technology, Pasadena
}

\begin{abstract}
An unplanned, but unique, experiment has given an in situ measurement of the strength of deforming subglacial till under the central region of a major valley glacier. We report on both planned and unplanned borehole investigations of the subglacial shear zone of Columbia Glacier, southeast Alaska. Basal samples, coring and down-hole water samples show that the fiord-filling lower reach of the glacier is underiain by a thin, $\sim 7-\mathrm{cm}$, veneer of rock debris. Fluidized debris intruded at least a meter up the borehole. At a higher site, $13 \mathrm{~km}$ from the terminus and above the fiord, probing, samples, and the bending of a drill stem, which was stuck in the basal zone for 5 days, showed that the basal till layer was $\sim 65 \mathrm{~cm}$ thick. Horizontal velocity of the till decreased monotonically downward from the ice/till interface. Till at the interface moved with the ice velocity. Plastic deformation of the drill stem gave an estimate of the strength of the basal till, which is normally described as a viscoplastic material. If the till is assumed to be either perfectly plastic or Newtonian viscous, then the strengths are as follows; the plastic yield strength of the till was $5.5 \times 10^{3} \mathrm{~Pa}$ ( $0.055 \mathrm{bar}$ ) with an upper bound of $1.3 \times 10^{4} \mathrm{~Pa}(0.13 \mathrm{bar})$, while the nominal viscosity was of the order of $2 \times 10^{8} \mathrm{Pas}\left(2 \times 10^{9}\right.$ poise), with an upper bound of $5 \times 10^{8} \mathrm{~Pa}$ s. In neither case is the till "strength" enough to supply the bulk basal shear stress to resist the glacier flow.
\end{abstract}

\section{INTRODUCTION}

Fast motion of most large valley glaciers and ice streams results from basal sliding or from shearing in the subbasal layers of rock debris (till). However, direct investigation of the ice/till/bedrock interface underneath active ice is difficult. Previous work, such as that by Boulton and Hindmarsh [1987], has investigated thin marginal ice, while Blake and Clarke [1989] have reported work on a small alpine glacier. Recent advances in hot-water drilling techniques have led to successes in both sampling and direct geophysical probing of the basal zone of large fast moving glaciers. Engelhardt et al. [1990a,b] and Blake et al. [1992] report recent results in obtaining samples of basal till and initial results in measuring in situ till deformation.

This paper reports on the basal shear zone of Columbia Glacier, a major fast-moving valley glacier in southeast Alaska, which was investigated through access holes bored in the ice with a hot-water drill. We interpret our downhole experiments to describe the physical conditions at the bed of the glacier. In particular, we report on a unique but unplanned experiment that occurred when a drill became stuck in the basal shear zone and was dragged for 5 days over the glacier bed. Analysis of the bent drill stem has yielded an in situ measurement of the strength of deforming basal till.

Columbia Glacier is a large $\left(1100 \mathrm{~km}^{2}\right)$ tidewater glacier. The terminus occupies a fiord about $5 \mathrm{~km}$ wide, which extends over $15 \mathrm{~km}$ into the Chugach Mountains and has a maximum depth of some $400 \mathrm{~m}$ below sealevel. Approximately $12 \mathrm{~km}$ above the calving terminus the fiord narrows before widening into the extensive upper region of the glacier. An icefall forms at this constriction, and ice speed doubles from the upper, slower,

Copyright 1993 by the American Geophysical Union.

Paper number 92JB01869.

0148-0227/93/92JB-01869\$05.00 region to the fast moving fiord tongue. The chaotic crevassing created in the constriction does not smooth out below the icefall, but persists into the low angle slope ( 1.5 degree) of the terminus region. Previous work [Krimmel, 1987; Walters, 1989; Meier et al., 1987] has shown correlations between the speed of the ice in the terminus region and both the water inputs to the glacier and the water pressure (tidal) on the snout. Current work by Fahnestock [1990] correlates ice speed with subglacial water volume. The terminus has retreated in the last 6 years as a result of increased calving [Meier et al., 1987; Krimmel, 1987].

\section{FIELD STUDIES}

Two hot-water drilling sites were established on the glacier, and holes were drilled to the bed to measure basal water pressures, reported elsewhere [Engelhardt et al., 1987]. The upper site was located approximately $13 \mathrm{~km}$ from the terminus, in the upper reaches of the icefall. The lower site, $6 \mathrm{~km}$ from the terminus, was located on the highly crevassed glacier surface below the icefall. The drill sites lay approximately on a single flow line, as indicated by proximity to a medial moraine traced with aerial photography. At each site, samplers were lowered to the bed, and investigation of the basal material was undertaken.

\section{Lower Drill Site}

The lower drill site was located on an ice serac in the crevassed lower reach of the glacier, some $160 \mathrm{~m}$ above sealevel and $\sim 520 \mathrm{~m}$ above the glacier bed. Ice surface speed was high, about $7.5 \mathrm{~m}$ per day [Meier et al., 1987]. Two holes were drilled $\sim 5 \mathrm{~m}$ apart using a hot-water drill. One hole was reamed to $7.5-\mathrm{cm}$ diameter and was used to lower instruments to the bed.

A sliding hammer, which could be lowered to the bed on a steel wire, provided initial indications of the physical character of the basal zone. The hammer consisted of a $20 \mathrm{~kg}$ weight 
that slides on a $1.5 \mathrm{~m}$ long, $1.2-\mathrm{cm}$ diameter steel shaft. The hammer could be repeatedly raised and dropped $\sim 1 \mathrm{~m}$, using the steel support cable. Either a 1.2-cm diameter mild-steel point (penetrometer point) or a coring tube (5- $\mathrm{cm}$ diameter), could be attached to the hammer shaft and driven into the base of the borehole. The barrel of the sliding hammer could be made watertight, and when the hammer and attached probe were lifted from the bed, with the hammer slide fully extended, a sample of fluid in the borehole at a level about $2 \mathrm{~m}$ above the bed was obtained.

The slide hammer was lowered 9 times at the lower site. There were three attempts to core, but only one sample was retrieved. This consisted of clean (no silt or clay) sand and gravel, with grain sizes from 0.5 to $5 \mathrm{~mm}$ in diameter. The flap valve on the core tube had not closed completely, and the sample may have been a residue which had been washed of finer material. Two other coring attempts resulted in blunting and bending of the cutting edges of the stainless steel core tube, and the flap valve was ripped or cut off.

The drive point of the penetrometer was painted with a waterproof ink, and it was lowered to the bed, where the slide hammer was operated to drive the point into the bed. The tip of the penetrometer was gouged and deformed (mushroomed), which indicated contact with a solid, angular surface. The paint was heavily scratched for $\sim 7 \mathrm{~cm}$ up from the tip and unscratched above, implying a veneer of penetrable till at the bed. Within a day of drilling or reaming the hole, the penetrometer no longer reached the bed. It would stop 1 or $2 \mathrm{~m}$ above the bed. Subsequent attempts to core either obtained slices of ice or partially jammed the penetrometer, indicating that the lowest few meters of hole had deformed. Since the water pressure in the hole remained close to the static ice pressure [Engelhardt et al., 1987], it is unlikely that the hole collapsed. A more likely explanation is that the bottom $2 \mathrm{~m}$ of the hole curved with the shearing of the basal ice.

Three samples of the borehole fluid from $\sim 2 \mathrm{~m}$ above the bed were obtained in the barrel of the slide hammer. These samples were all extremely turbid. The highest concentration was $54 \%$ by weight of silt and fine sands and included particles up to 7mm diameter, which was the sampler inlet size. This unexpected result, which implies that the sampler was actually buried in at least $2 \mathrm{~m}$ of debris, contradicts the picture of $7 \mathrm{~cm}$ of till, inferred above. However, subsequent measurements elucidated the situation and are discussed below.

\section{Borehole Turbidity and Water Velocity Profiles}

Both turbidity and water velocity were measured down the length of the borehole. Turbidity profiles were obtained in the borehole using a light transmission turbidity meter (uncalibrated). The water was clear to a depth of $342.5 \mathrm{~m}(\sim 180 \mathrm{~m}$ above the bed) and essentially opaque below that level. Numerous water samples confirmed the turbidity. A sample taken from $5 \mathrm{~m}$ above the bed had $0.5 \%$ by weight of mostly silt and clay-sized particles, although water samples up to 180 $\mathrm{m}$ above the bed still contained fine sand particles up to $0.2 \mathrm{~mm}$ (with a calculated settling velocity of $-2 \mathrm{~cm} / \mathrm{s}$ ). Water samples taken in the upper part of the hole, above a depth from the surface of $342 \mathrm{~m}$, were clear. (A profile taken with a scatteredlight turbidity meter showed the confusing result of no variation down the hole. This was a result of clear water in the upper section of the hole and opaque water in the lower half, both of which scatter virtually no light!)
A water velocity profile was obtained with a self-heated thermistor probe. Damage to the velocity probe (but not the direction thermistor) forced us to estimate the velocity by raising or lowering the probe in the hole until a null reading was reached. The rate of manual lowering or raising was the velocity measure. Below the $342.5 \mathrm{~m}$ level, the velocity was approximately $2 \mathrm{~cm} / \mathrm{s}$ up the hole, while above that point the water was stationary. Although the errors in the water velocity measurements were the same magnitude as the velocity, the measurements do suggest that the turbid water was rising from the bed and entering an englacial hydraulic system.

The turbidity of the rising column of water was observed for over 24 hours. Profiles of slightly lower turbidity that correlated with a dip in the water pressure during the single night of observation (July 30 to 31 ), implied that flow was less vigorous when water pressure in the hole was low. Since flow was observed for more than half a day, its continued existence implied an englacial system, $\sim 180 \mathrm{~m}$ above the bed of the glacier, that connected to a sink for the water.

This upward water flow can explain the extreme debris content of the "water" sample taken $2 \mathrm{~m}$ above the bed (described above). A velocity of $2 \mathrm{~cm} / \mathrm{s}$ is more than adequate to fluidize a bed of sands and fine gravels [Middleton and Southard, 1977]. The sands and gravels were probably flushed into the hole from the surrounding bed, forming a fluidized column at the bottom of the hole. It was this fluidized column that was sampled by the slide hammer barrel.

\section{Upper Drill Site}

The upper drill site was located $\sim 13 \mathrm{~km}$ from the terminus, $500 \mathrm{~m}$ above sea level and $-950 \mathrm{~m}$ above the bed. The glacier surface was less chaotic than at the lower site, and the surface velocity was only half, at $3.5 \mathrm{~m}$ per day [Meier et al., 1987]. Three boreholes reached the bed. The second of these, with a depth of $974 \mathrm{~m}$, was used to sample the basal zone.

Samples of clear water were obtained down to a depth $750 \mathrm{~m}$ below the surface (the in-hole water sampler was the largest diameter device and would not go below this point). Attempts to core the basal zone failed; the cutting edges of the core tube were blunted, presumably by rocks. Penetrometer tests were equivocal, with some scratches on the tip to about $20 \mathrm{~cm}$, but with little metal deformation to indicate bedrock had been reached. Since the tip on the penetrometer is $40 \mathrm{~cm}$ long, this implies that bedrock was buried beneath more than $40 \mathrm{~cm}$ of till but only if the sediment was sufficiently soft to allow penetration without major scratching. At $1 \mathrm{~km}$ depth, stretch in the support wire allows little information "feedback" from the bed, resulting in uncertainty as to whether or not the slide hammer was operating freely.

Water samples taken in the barrel of the penetrometer at the bed were turbid ( $1 \%$ by weight), with the bulk of the sample in the silt and clay sizes and little of the sand or larger fraction found in the fluidized material at the lower site hóle. A mold of the borehole bottom was taken with a butter-filled core tube. Several grains and pebbles stuck in the butter, and these together with the impression in the butter showed a mixed grain size sandy gravel with sizes ranging from less than $0.5 \mathrm{~mm}$ to a subrounded pebble $1.1 \mathrm{~cm}$ diameter.

\section{BENT DRIIL STEM}

In the third hole drilled at the upper site, the drilı stuck at the base of the ice. Attempts were made to raise the drill soon after 
perceptible downward progress had stopped, but the stem resisted $\sim 1000 \mathrm{~N}$ tension. Hot water was pumped down the hole for 7 hours after the drill became stuck, and at various times subsequently while trying to recover the drill hose and stem. The hose and stem were recovered 5 days later by applying high $(3000 \mathrm{~N})$ tension. After pulling the stem free of the bed, abnormally high tension ( $1000 \mathrm{~N})$ had to be continuously applied to bring the stem to the glacier surface. The brass stem was bent into a sweeping curve (Figure 1) which dramatically proved that it had been stuck in the basal shear zone. Scratches on the stem and the exact shape of the bending are used below to infer some of the properties of the basal zone and take advantage of this unique and unplanned experiment.

The shape of the bent stem, as removed from the borehole, is shown in Figure 1. The data for Figure 1 were obtained with a micrometer with a precision of $0.025 \mathrm{~mm}$ and with measurements spaced at $2.54-\mathrm{cm}$ intervals along the stem. Repeat measurements showed less than $0.05-\mathrm{mm}$ scatter. The $3.2-\mathrm{m}$ stem was bent more at the bottom or tip end, with a maximum in curvature about $65 \mathrm{~cm}$ above the tip. In its bent state, the tip makes an angle of $20^{\circ}$ with the vertical (as defined by the upper unbent section of the stem). The body of the stem was striated longitudinally over its whole surface, while the lowest $60 \mathrm{~cm}$ had cross-cutting, subhorizontal striations on the sides of the stem. Striations appear to be caused by differential motion between the stem and rock fragments, and comparison with other used stems showed that the longitudinal striations arise in normal drilling and are probably caused by minor debris in the bulk glacier ice. The subhorizontal striations, however, have only been found on the bent stem. These striations are subparallel, and are oriented so that they would be approximately horizontal if the stem tip was bent to $30^{\circ}$ from the vertical instead of the observed 20. Most of the subhorizontal striations are short and lie in two bands subtending about $20^{\circ}$ of the circumference on each side of the curve of the stem. There were no striations or marks near the maximum curvature point (65 cm from the tip), such as might be expected if the bending force had been applied by rocks impinging on the stem instead of ice.

The lowest $29 \mathrm{~cm}$ of the stem is the nozzle, which is machined out of solid brass and shows less curvature than the hollow brass tubing (Figure 2) of the body of the stem. The nozzle was striated both longitudinally and subhorizontally, but most notably, it showed a set of deep $(\sim 0.5 \mathrm{~mm})$ gouges starting at $18 \mathrm{~cm}$ above the tip on the convex side of the stem curvature and running down toward the tip, with some gouges splaying to the sides of the nozzle. Small flakes of rock were still embedded in the gouges, and the plastically deformed metal at the gouge edges clearly showed that rock had scraped down the nozzle to the tip. Such gouges strongly imply that the stem was bent by being forcibly dragged over a rock. The lack of gouges (or deep striations) above the tip imply that the force couple that resisted the rotation of the stem, and helped cause the bending, resulted from the top of the stem being held in the ice.

Figure 3 shows an estimate of the density of subhorizontal striations in the bands. Density was measured by observing the cumulative widths of the subhorizontal striations on a line drawn down the side of the stem. The widths were measured with a 5 power loupe and reticle, with striations at the limit of resolution assigned a width of $0.1 \mathrm{~mm}$. Density is the sum of the striation widths in a $1-\mathrm{cm}$ length of stem, divided by $1 \mathrm{~cm}$. Striation density decreases from the tip to zero at about the 60 - $\mathrm{cm}$ point. The density is noticeably higher in the lowest $15 \mathrm{~cm}$ as a result of splaying of the gouges (mentioned above) to the sides of the tip. If the gouges are ignored, the subjective impression is a continuous and linear decrease in striation density from the tip to the $60-\mathrm{cm}$ point.

Subhorizontal striations imply sideways movement of the stem through either dirty ice or basal debris. Lack of subhorizontal striations on the upper stem indicates that either the upper stem section did not move sideways or else moved through clean ice. The increase in striation density towards the stem tip implies that either the number density of rock fragments increased downward from the $65-\mathrm{cm}$ point or that differential motion between the stem and rock fragments increased toward the tip.

The depths of adjacent boreholes indicate that the drill stem was in the basal zone when it was bent. The hole in which the stem stuck was $1 \mathrm{~m}$ deeper than the borehole used for bed sampling, which was $280 \mathrm{~m}$ upglacier.

\section{Forces Needed to Deform the Stem}

If we assume that the stem was simply bent at the bed and did not go through a bending/unbending cycle other than relaxation, then the deflection curve of the stem records the forces that bent the stem at the glacier base, at least in the lower $2 \mathrm{~m}$ of the stem which retains a permanent bend. Only an upper bound is placed on the forces applied to the upper (straight) meter of the stem. In the following, we refer to two curves (or states) for the stem; the first is the fully loaded curve, which is the shape of the stem, while maximum bending stresses were being applied and producing both elastic and plastic bending. The second curve is the residual, which is the curve of the stem after it was taken out of the glacier. It is assumed that the residual state is the result of the relaxation of the fully loaded curve. When the stem was bent, the outermost "layer" of brass was strained plastically, the bulk of the inner part of the stem only deformed elastically. Here, inner and outer refer to a radial distance from the stem centerline in the plane of curvature of the stem. The shape of the residual curve is a balance between the elastic straightening stresses of the inner layers and the resistance to straightening of the plastically strained outer layers. Figure 1 shows the residual deflection curve of the stem (subscript $r$ is used to indicate the residual deflections, while deflections of the stem under load are unsubscripted). The internal stress state of the stem in its residual state can be estimated from an appropriate rheological model of the stem. Once the residual stress state is known, the forces needed to deform the stem to its fully loaded state from which it will relax to its residual state, can be calculated.

In the following we assume that the stem was not plastically straightened while being extracted. This assumption is based on a loading test of the bent stem that demonstrated that the stem can be elastically straightened enough to fit back up through a nominal 12-cm diameter borehole by applying a $\sim 500 \mathrm{~N}$ force sideways to the bent stem. An additional numerical test was performed. The model developed later in this paper was used to calculate that the stem can be completely straightened, and even bent into a slight reverse curve, without inducing plastic strains. This shows that the stem was not plastically straightened by pulling it out of the borehole, since if the stem had plastically strained to fit back up the $12-\mathrm{cm}$ borehole, then plastic strain would be induced in the (modeled) stem if it was straightened beyond that slight curvature. 
STEM DEFECTION

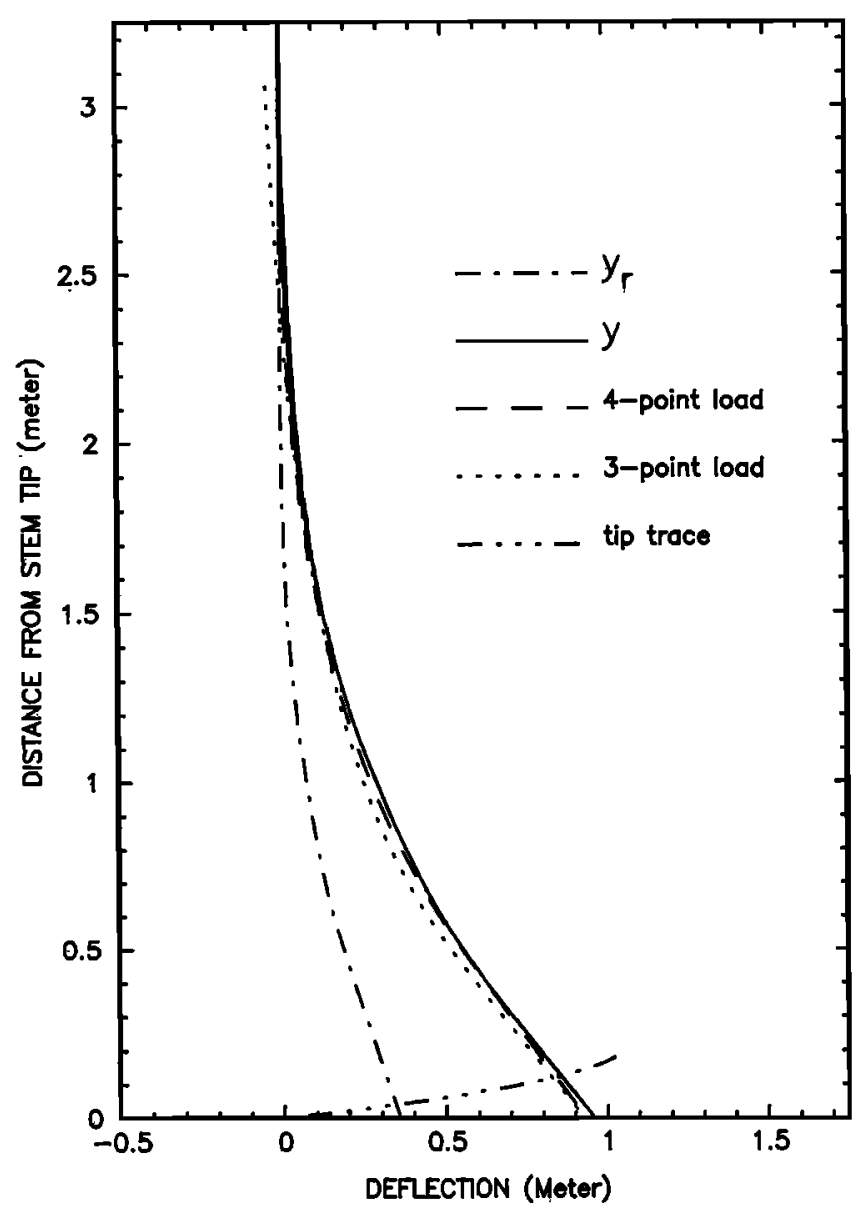

Fig. 1. Observed residual deflection of the drill stem $\left(y_{r}\right)$. The solid line $(y)$ shows the fully loaded deformation of the stem. This is the reconstructed plastic plus elastic deformation based on equation (5). The dashed line shows the plastic plus elastic deformation of the stem calculated from the "4-point" side-loading model, and the dotted line is for the "3-point" model (see text). The vertical distance scale follows the stem center line. The short curve rising from zero shows the path swept by the stem tip as it was bent, referenced to a vertical scale.

The stem consists of two concentric brass tubes, with the included annulus packed with lead shot (see Figure 2). The inner and outer tubes are "red" brass $(85 \% \mathrm{Cu}$ and $15 \% \mathrm{Zn})$, which may be approximately described as an elastoplastic [Murphy, 1947] with so-called work-hardening plasticity as shown in Figure 4. The inclusion of the work-hardening behavior in the following discussion introduces some algebraic complexity which cannot be justified on the basis of increased numerical accuracy of the final calculated forces; however, it was found that including the work hardening increased our ability to model the precise shape of the bent stem. The inner tube adds little to the bending strength of the stem since the bending resistance is proportional to the square of the diameter. We assume that the loose lead shot packing does not add to the bending strength.

To calculate the bending forces in the stem, we start with elastic beam-bending equations [e.g. Byars and Snyder, 1969]

$$
E I y^{\prime \prime}=M(z) \quad \frac{d^{2}}{d z^{2}} M=f(z)
$$

where $z$ is the vertical coordinate and $y(z)$ is the lateral deflection of the stem $\left(y^{\prime \prime}=d^{2} y / d z^{2}\right.$, which is the curvature of the stem under load). The product of the elastic modulus $E$ and the (so-called) moment of inertia $I$ parameterizes the resistance to bending of an elastic beam. The force distribution on the stem which causes the deflection is $f(z)$, and $M(z)$ is the bending moment distribution. If the stem is bent sufficiently, then the brass in the outer (and inner) "layers" of the curve will strain beyond the elastic limit, and permanent plastic deformation will occur. Beyond the elastic limit, (1) is an incomplete description of the stem bending.

A bending test on the upper, unbent, section of the stem measured the elastic modulus $(E)$ as $1.1 \times 10^{11} \mathrm{Nm}^{-2}$ and the elastic limit $(Y)$ was found to be $-3.1 \times 10^{8} \mathrm{Nm}^{-2}$. The elastic "moment of inertia" for the stem is $2.5 \times 10^{-8} \mathrm{~m}^{4}$ and for the elastic limit of the stem to be exceeded, bending moments of the order of $500 \mathrm{Nm}$ are required. The strains seen in the bent stem are in general less than 0.01 , which are below strains typical of fully developed plastic response in brass (see dashed line in Figure 4) and for this reason we assume the stem is a workhardening plastic material for stresses above the elastic limit ("incremental work-hardening modulus" $W=10^{10} \mathrm{Nm}^{-2}$ [ $W=d \sigma / d \varepsilon]$ ). This approximates the "roll-off" toward perfect plastic behavior seen in a typical yield curve for brass (Figure 4). Strain beyond the elastic limit is assumed to be inelastic and therefore nonrecoverable.

When the stem is bent so that the outer layers deform plastically, the ratio of the amount of brass which is bending elastically (near the axis) to brass which is deforming plastically, depends only on the local curvature. Thus the first equation in (1) can be recast to give the bending moment

$$
G\left(y^{\prime \prime} ; E, Y, W\right) y^{\prime \prime}=M(z)
$$

where $G$ gives the resistance to bending of the elastoplastic stem (replacing the elastic term $E I$ in (1)). The function $G$ depends on the material parameters, $E, Y, W$, and on the ratio of elastically to plastically deforming material in the stem. parameterized by $y^{\prime \prime}$. An algebraic manipulation (outlined in the appendix) can be performed for the specific geometry of a thin-walled tube to derive an expression for $G$ that includes the work-hardening plastic rheology. This expression is

$$
\begin{aligned}
& G\left(y^{\prime \prime} ; E, Y, W\right)= \\
& 2 E R^{3} t\left[\frac{\pi}{2} \frac{W}{E}+\left(1-\frac{W}{E}\right)\left(\sin ^{-1} \zeta+\zeta\left(1-\zeta^{2}\right)^{1 / 2}\right)\right]
\end{aligned}
$$

where $t$ is the tube wall thickness, $R$ is the radius of the stem, $W / E=0.11$ from Figure 3 , and $\zeta$ is the fractional size of the elastic zone compared to $R$, defined by

$$
\begin{aligned}
& \zeta=\frac{Y}{y^{\prime \prime} R E} \quad y^{\prime \prime} \geq \frac{Y}{R E} \\
& \zeta=1 \quad y^{\prime \prime}<\frac{Y}{R E}
\end{aligned}
$$

Note that in equations (1)-(4), $y^{\prime \prime}(z)$ is is the curvature of the stem while it was being deformed, in other words, the fully loaded curvature of the stem.

\section{Reconstructing the Elastic Plus Plastic Bending of the Stem}

The first step in calculating the forces that bent the stem is to reconstruct the fully loaded stem curvature from the residual curvature. This is only possible where there is residual plastic deformation. In the upper meter of the stem, the deformation is close to zero, which implies that the the forces were below that needed to exceed the elastic limit of the stem. However, in the 


\section{CROSS-SECTION OF STEM}

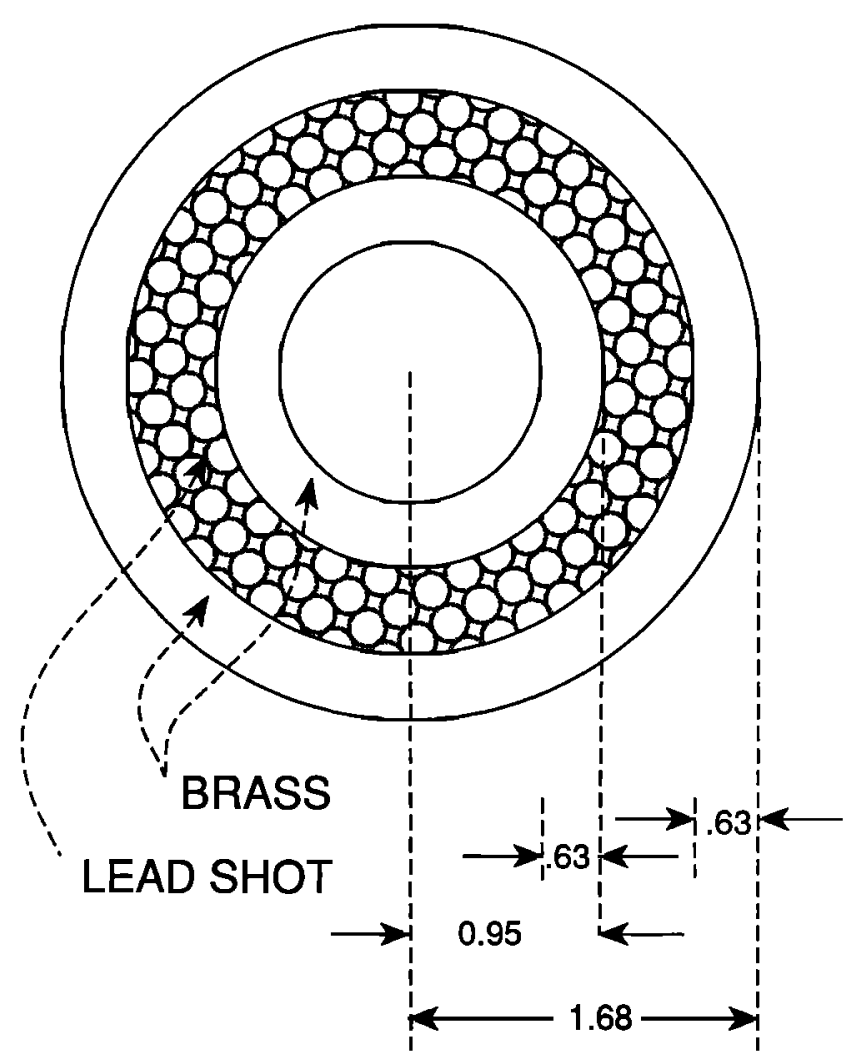

Fig. 2. Cross section of the hollow brass stem, showing the inner packing of lead shot and the internal tube of $1.9 \mathrm{~cm}$ brass. Dimensions in centimeters.

STRIATION DENSTTY

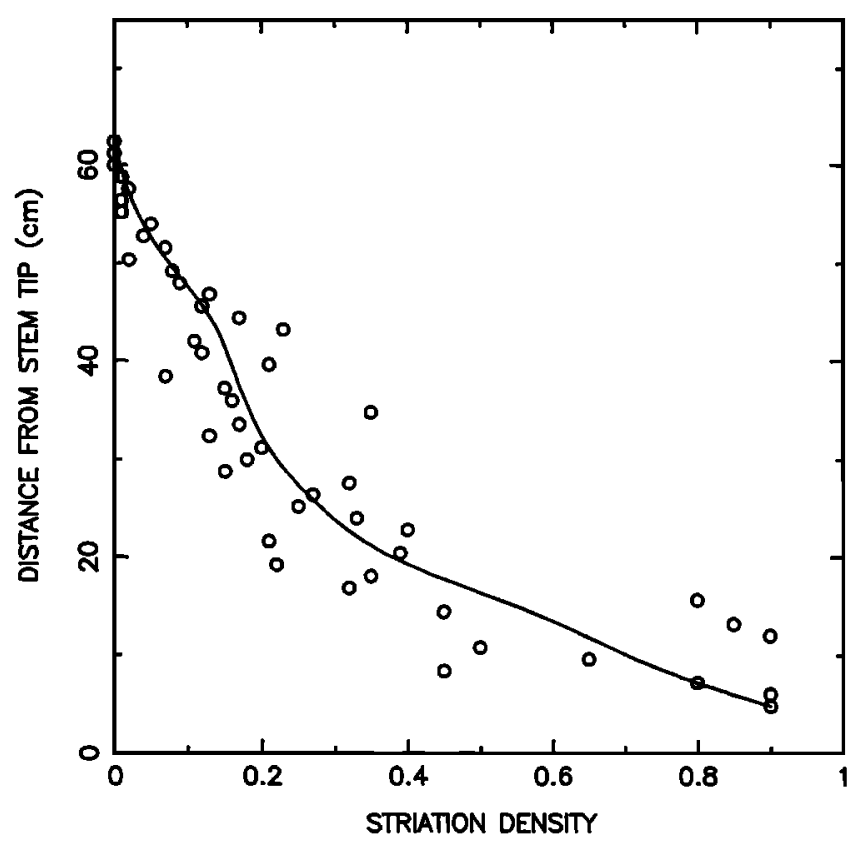

Fig. 3. Density of striations on the stem. The striations were counted and measured with a $5 x$ hand lens and are expressed as a percentage of a $1-\mathrm{cm}$ line covered by striae. Distances are measured from the tip. The solid curve shows the data afler smoothing with a digital filter. lower $2 \mathrm{~m}$ the elastic limit was exceeded, and the stem retains some curvature after relaxation. This residual curvature is the result of a force balance between the plastically deformed outer layers of the stem resisting straightening, and the elastic, axial region of the stem resisting bending. A similar derivation, as was done for (3), was performed to show that the fully loaded curvature of the stem can be recovered by solving the algebraic equation

$$
y^{\prime \prime}(z)=\frac{y_{r}^{\prime \prime}}{\left(1-\frac{2}{\pi} \sin ^{-1} \zeta-\frac{2}{\pi} \zeta\left(1-\zeta^{2}\right)^{1 / 2}\right)}
$$

for $y^{\prime \prime}$. where $y_{r}{ }^{\prime \prime}(z)$ is the residual curvature. In the limit as the residual deformation $\left(y_{r} "=0\right)$ goes to zero, (5) gives the maximum elastic curvature $\left(y^{\prime \prime}=Y / R E\right)$. Thus in the upper meter of the stem (5) in general overestimates the unrelaxed curvature and in the following only an upper bound is found for the forces on the the upper meter and the lower $0.28 \mathrm{~m}$ (nozzle).

The estimation of $y^{\prime \prime}$ using (5) and the application of (2) allows the direct calculation of the bending moment distribution $(M)$. The second integral of $y^{\prime \prime}$ gives the fully flexed deflection curve ( $y$ ) and the second derivative of the bending moment gives the force distribution $f(z)$. Equations (2) to (5) were implemented as an iterative numerical routine.

\section{Calculating the Force Distribution That Bent the Stem}

The data on the bent stem are the deflections $\left(y_{r}\right.$ in Figure 1), but the calculation of the bending moment and force distribution requires the second and fourth derivatives of the deflections. Measurement errors and surface roughness of the stem introduce noise in the deflection data, which causes a poor signal-to-noise ratio, especially in the calculation of the fourth derivative. The data and the derivatives have been smoothed with a center weighted 5-point smoothing filter as a compromise between damping and smearing the signal and losing the signal in the noise. With this caveat, equation (5) was applied to $y_{r}$ to calculate the fully loaded deflection $(y)$ curve which is shown in Figure 1 . The bending moment $(M)$, and the force distribution $(f)$ are calculated from $y$ with equations (1) and (2) and the results given in Figures 5 and 6 . Most of the subsidiary peaks in Figure 6 merely reflect noise in the data.

Figures 5 and 6 are dominated by a peak at $65 \mathrm{~cm}$ from the tip (as was expected from the observed increased curvature at that point), and, consequently, the force distribution can be approximated as a sideways point loading at the $65-\mathrm{cm}$ point, balanced by forces at the top and bottom of the stem (which do not appear in Figure 6 since the top and bottom of the stem are not modeled). A close representation of the loading is the "4point" load as shown by the dotted line in the moment figure. The 4-point load has a major side force at $65 \mathrm{~cm}$, a lesser one at $2 \mathrm{~m}$, and balancing forces at top and bottom. This loading produces a deflection curve that lies within a few percent of the $y$ curve in Figure 1 . The bending of the stem is closely modeled by the 4-point loading. However, the location of the second load and whether it is a point load or distributed, makes only small differences to the resulting deflection curves. This is illustrated by the extreme case of the 3-point loading curve shown in Figure 5, where a single higher load is applied at 65 $\mathrm{cm}$. The resulting deflection of the stem is shown in Figure 1. The deflection curve is positioned to emphasize the comparison in the lowest $2 \mathrm{~m}$, and it is seen that the 3-point loading overemphasizes the bend at $65 \mathrm{~cm}$ and underdeflects the stem in 
the upper meter. However, considering the accuracy of both the data and the modeling, it is not reasonable to define the exact location or distribution of the secondary side load.

Thus we conclude that the stem was bent by a side loading, with the major load point at $65 \mathrm{~cm}$, and a bending moment maximum between 710 and $780 \mathrm{Nm}$. There was additional side loading above $65 \mathrm{~cm}$, up to about $2 \mathrm{~m}$. It should be noted that our interpretation of the cause of the bending of the stem uses the force distribution on the stem as part of the data, but the final calculations on the strength of the basal debris depend only on the moment at the $65-\mathrm{cm}$ point, and this varies little between the 3- and 4-point model.

\section{Mode of Bending of the Stem}

The stem was bent by a force of magnitude $-2500 \mathrm{~N}$ in the region of $65 \mathrm{~cm}$, plus counter forces at the bottom and top. In the following, we identify the probable cause for the bending, and in the discussion on lateral melting of the stem, a possible mechanism for delocalization of forces is presented.

As a starting point we note that if the stem was in ice, then the lateral forces on the stem, and presumably the enclosing ice (Figure 6), were well below the forces needed to cause significant relative motion between the stem and the ice by either regelation or ice deformation. The only other way for the stem to move laterally through clean ice would be by ice melting. For most of the time that the stem was at the bed, it was unheated; however, it was heated during the first 7 hours. The water temperature going through the stem was on the order of $2^{\circ} \mathrm{C}$ as calculated from the observed drilling speed and from a thermal model of drilling [Humphrey and Echelmeyer, 1990]. This heat input would allow the stem to melt sideways by conduction (through the brass) at a rate less than $2 \mathrm{~cm} / \mathrm{hr}$. We ignore any melting by the water flowing back up the hole from the drill nozzle, since it would flow in the open part of the borehole, not where the stem pressed against the ice. The ability for the stem to move sideways by melting in the first hours at the bed complicates the following discussion. However, the lateral melt rate is much less than the glacier sliding velocity, and the total lateral melt in the 7 hours of heating would be only about $15 \mathrm{~cm}$. We therefore assume lateral melting was a minor component of the motion but note that lateral melting may be sufficient to cause the point of application of the lateral bending forces to vary in time, in essence smearing out the force location, and this is the probable cause of the better fit to the deflection data by the 4-point, instead of the 3-point model.

Although we have elucidated the stresses on the stem and have also noted that the lower $65 \mathrm{~cm}$ moved differentially through either debris or debris-rich ice, it is not possible to describe unequivocally the environment that bent the stem. It is likely that the stem protruded from clean ice (at the $65-\mathrm{cm}$ point) into a basal till layer. This is consistent with the force profile, striations and with the sampling, turbidity, and penetrometer data. In the following, this style of bending is assumed, however, there are other possibilities. The most feasible alternative is that the stem was bent as a passive element in the overall strain field at the glacier bed, however, it is hard to explain the striation pattern for this scenario.

The time history of the bending is not completely constrained. However, it is noteworthy that the stem became firmly stuck only a short time after it reached the bed. Indeed, it was trapped less than an hour after reaching the bottom. This occurred in spite of the fact that the stem was being heated and that it was presumably sitting in a melted hole that was some-

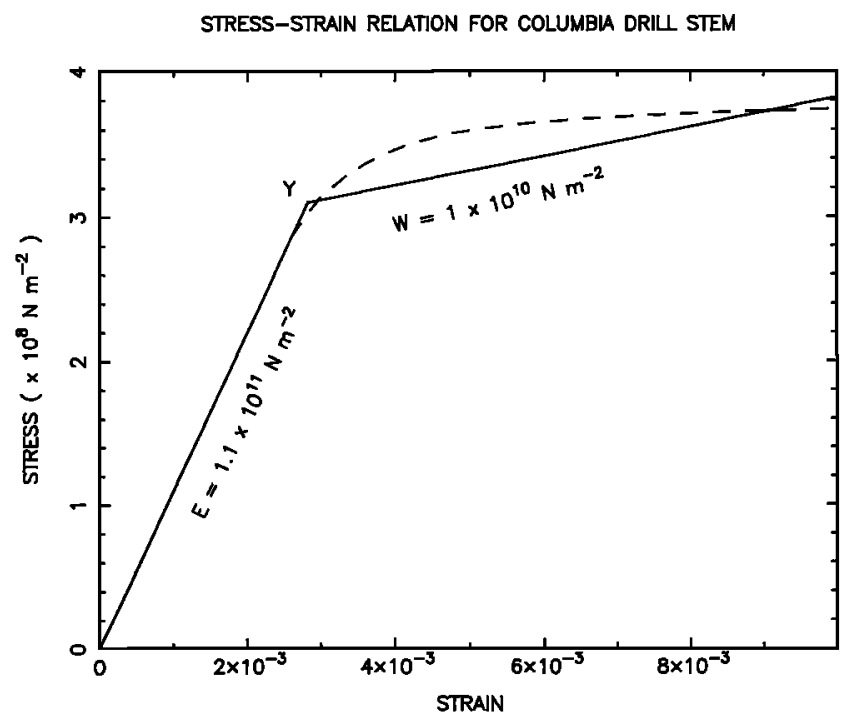

Fig. 4. Stress-strain relation used for the Columbia drill stem. The elastic modulus $E$ was measured by bending the original stem. The elastic limit $Y$ was measured by observing the loading that produced a permanent bend. The dashed curve is typical for brass $(90 \% \mathrm{Cu}, 10 \% \mathrm{Zn}$ [from Murphy, 1947]). The incremental work-hardening modulus $W$ is chosen to approximate the typical plastic behavior, see text.

what larger than the stem diameter. If the deformation of the stem was uniform in time for 5 days, then in the first hour or so it would have only bent a few millimeters. This strain and implied force (on the order of 10 s of newtons, from the stem modeling) was unlikely to be sufficient to pin the stem against more than $1000 \mathrm{~N}$ tension, applied in an attempt to free the drill. For the stem to have been pinned immediately, something had to have acted quickly; the stem had to have been subjected to large stresses, rapidly applied.

If, as was argued above, the stem protruded from the ice into a basal shear zone, then it was subjected to a shear displacement of some $4 \mathrm{~m}$ per day. If the stem completely spanned the basal shear zone, it would have experienced between 5 and 10 $\mathrm{cm}$ of total shear across the layer during the time before the first attempt to retract the stem. Such a complete spanning of the basal zone is a plausible means of trapping the stem. A problem is that such a shear rate could not be maintained in the stem for 5 days, or it would have been either torn apart or grossly distorted.

The above discussions can be summarized to give a description of the bending of the drill stem, which is sketched in Figure 7. Shortly after drilling to the bottom of the ice and after drilling through $0.65 \mathrm{~m}$ of basal till (our tests on soil demonstrate the ease of drilling into unconsolidated sediments), the stem was advected horizontally into a bedrock protrusion or a stationary boulder. The height of the rock was approximately $18 \mathrm{~cm}$ above the stem tip as indicated by the location of the start of the major gouges. As a consequence of the sliding velocity of 3-4 m per day, the stem deformed and bent, until the curvature of the stem caused it to shorten enough to ride over the rock (Figure $7 b$ ). The calculations used to produce Figure 1 show that the stem is $-18 \mathrm{~cm}$ shorter in its fully loaded state than when it was straight. It would have ridden over the obstruction about 6 hours after being pinned. The striations are a result of dragging the stem through a basal till layer some 65 $\mathrm{cm}$ thick, while the lack of striations higher on the stem implies that it was in clean ice and/or that no differential motion occurred between the stem and its surroundings. The increase 
BENDING MOMENT

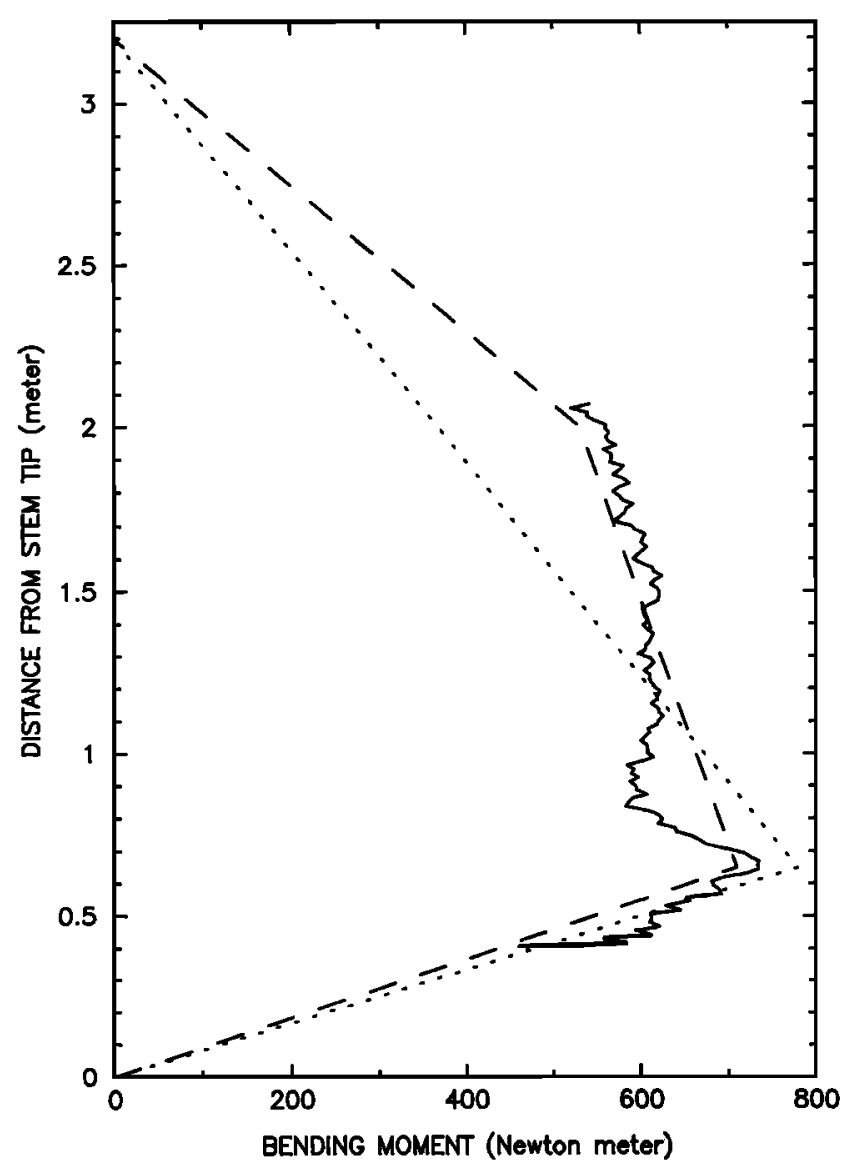

Fig. 5. Bending moment of the reconstructed fully bent stem. Only the region from $25 \mathrm{~cm}$ to $200 \mathrm{~cm}$ has been modeled; the lower $25 \mathrm{~cm}$ includes the nozzle, and the upper meter was not plastically deformed, and therefore the bending moment is indeterminate, but less than 500 $\mathrm{Nm}$. The dotted line shows the moment distribution for "3-point" side loading (see text) and the dashed line gives the moment for the "4-point" model.

in striation density toward the stem tip implies that the relative velocity between the stem and the till increased downward from the $65-\mathrm{cm}$ point, and from Figure 3 there is evidence that the differential velocity between the stem and the till increases linearly with depth from the base of the ice; this implies a constant shear rate with depth in the till.

After riding over the obstruction, the stem would not have relaxed fully. Figure $7 c$ illustrates that some sideways loading and elastic bending would have resulted from motion of the stem through the basal till. The angle of the bending while the stem was dragged for 5 days through the till is recorded by the angle of the subhorizontal striations. These indicate that the stem was bent at about $30^{\circ}$ from the vertical, as opposed to the $20^{\circ}$ of the residual state.

\section{BASAL TILL LAYER}

Assuming that the stem was deformed as described, the lower part of the stem was dragged through the basal till layer for 5 days after the initial deformation occurred. Therefore we can make two estimates of the force loading on the stem caused by the till. An upper estimate of the loading is that it had to be less than, or equal to, the loading required to produce the fully loaded curvature. A second estimate of the loading on the stem from the till can be obtained by calculating the stresses required to elastically bend the already plastically deformed stem to the $30^{\circ}$ angle recorded by the striations. This second estimate is probably more accurate but rests more on the accuracy of our deduced bending scenario. These estimates of the loading on the stem from the deformation of the till past the stem gives information on till strength. To extract this information, we need a rheological model of the till.

Deforming subglacial till has been characterized as a nonlinear viscoplastic material [Boulton and Hindmarsh, 1987]. Since the rheology is not well known and our data is insufficient to define the rheology of the till, we proceed by assuming the till has one of the two end-member rheologies, either plastic or Newtonian viscous.

\section{Plastic Yield Strength of the Till}

There is evidence that the till behaves as a plastic material. The pattern of subhorizontal striations forms narrow bands down each side of the stem, implying that there was a layer or zone of till advecting with the stem, both in front and behind, as the stem moved through the till. These nondeforming zones protected the surface from scratching. This is a plastic type of behavior.

An upper bound on the plastic yield stress of the till can be obtained by calculating the plastic strength in the till required to bend, but not break, the stem which was dragged through it. The problem may be defined in plane strain, as the dragging of a stiff cylinder through a plastic medium. We further approximate by considering the cylinder to be a flat line indenter of the same width as the diameter of the stem [Hill, 1956]. The passage of the stem through the till is described by the passage of a positive and "negative" indenter. This gives an expression.

$$
\sigma=2(\pi+2) k
$$

where $\sigma$ is the stress on the stem which results from drag on till with a yield strength of $k$. Since (6) assumes perfect plasticity for the till, the shear rate in the till is unimportant as long as some (plastic) motion occurs between the stem and the debris. The yield strength of the stem places an upper limit on the bending moment (due to $\sigma$ ) that could be applied to the lower $65 \mathrm{~cm}$ of the stem, which in turn gives an upper limit on $k$. Equation (6), multiplied by the moment arm, was integrated over the lowest $65 \mathrm{~cm}$ of the stem to obtain the bending moment caused by the till, in terms of the unknown yield strength $k$. Since the maximum bending moment in the stem did not exceed $\sim 750 \mathrm{Nm}$, we get an upper bound of $13,000 \mathrm{~Pa}$ $(0.13 \mathrm{bar})$ on the plastic yield strength of the till.

A more accurate estimate is based on the moment required to bend the stem to the $30^{\circ}$ angle of the striations. This estimate relies on the time history of the bending scenario. If the stem had to be bent from its initial, straight, state to an angle of $30^{\circ}$, then moments of the order of $600 \mathrm{Nm}$ would have been required. However, since the stem had already been plastically deformed, to the fully loaded curve, then to maintain an angle of $30^{\circ}$ only required a purely elastic moment of $\sim 310 \mathrm{Nm}$. This is the moment required to flex the stem from the residual curve to $30^{\circ}$. Again, using (6), this moment yields an estimate of the plastic yield stress for the till of $5500 \mathrm{~Pa}$ (0.055 bar).

\section{An Effective Viscosity for the Till}

Some models of till have emphasized viscous behavior [Boulton and Hindmarsh, 1987; Alley, 1989]. Indeed, the striations imply a viscous behavior in that the shear rate appears to be 
FORCE LOADING ON STEM

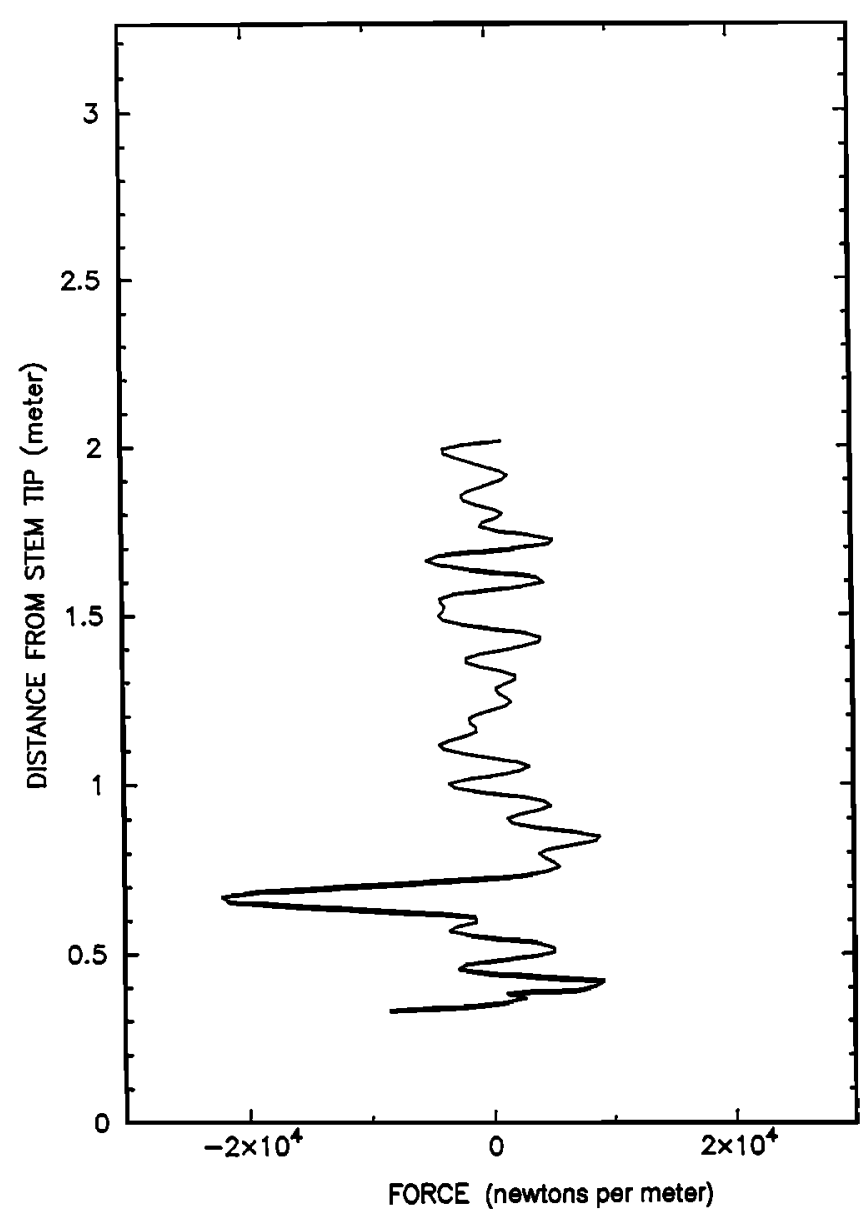

Fig. 6. The forces needed to deform the stem. As in Figure 5, the lowest $25 \mathrm{~cm}$ and the upper meter are undetermined.

constant with depth, which is not a perfect plastic behavior. An argument can be made that some form of viscous response could be expected if the till behaves as a power law fluid. Since the till was being sheared by the bulk sliding of the glacier, an effective viscosity is established with respect to small additional strains. However, the strains associated with the stem's motion through the till would not have been small close to the stem. Despite this, for the following calculation we assume that the drag of the stem through the already shearing debris can be approximately treated as a problem in linear viscosity and use it as a means of measuring the "effective" viscosity in the basal zone.

The drag force on a cylinder at low Reynolds number is

$$
F_{d}=C_{d}\left(\rho U^{2} \frac{D}{2}\right), \quad C_{d} \cong \frac{4 \pi}{R e}\left[\log _{e} \frac{3.7}{R e}\right]^{-1}
$$

where $F_{d}$ is the drag per unit length of the cylinder, $U$ is the relative velocity difference between the fluid and the stem, $D$ is the stem diameter, and $p$ is the debris density. Equation (7) uses the first term in the Oseen expansion [Van Dyke, 1975] to estimate the drag coefficient $\left(C_{d}\right)$ to avoid the classic Stokes' paradox. ( $R e$ is the Reynolds number, $R e=\rho U D / \mu$, and $\mu$ is the fluid viscosity.)

The shear rate in the debris is assumed to be constant with depth. The differential velocity between stem and till increases with depth, up to the ice sliding speed at a depth of $65 \mathrm{~cm}$.
From the previous section on the deformation of the stem, the maximum bending moment in the stem was about $750 \mathrm{Nm}$. This moment puts an integral constraint on $F_{d}$ and using (7) and a value for $\rho$ of $2000 \mathrm{~kg} \mathrm{~m}^{-3}$, the viscosity of the basal layer could not exceed $5 \times 10^{8} \mathrm{Pas}\left(5 \times 10^{9}\right.$ poise) if the stem was dragged through it without further bending.

The observation that the stem was only at an angle of $30^{\circ}$ for most of the dragging, with only $310 \mathrm{Nm}$ needed for the bending, allows a better estimate to be obtained (as in the previous section). Using (7) results in a viscosity estimate of approximately $2 \times 10^{8} \mathrm{Pas}\left(2 \times 10^{9}\right.$ poise).

\section{DISCUSSION}

The rheology of the debris is certainly more complex than the two end-member cases discussed above. However, some indication of the strength of the till has been found. The basal shear stress at the upper site (approximately $1 \mathrm{bar}$ ) can be compared with the inferred strength of the till. For the case of a plastic till, the applied shear stress is much greater than can be supported by the -0.055 bar strength of the till. If, on the other hand, the till were Newtonian viscous, and shearing in a layer $65 \mathrm{~cm}$ thick, at a total shear of $4 \mathrm{~m}$ per day, and if it were resisting the basal stress of 1 bar, then it would have needed to have had a material viscosity of the order of $5 \times 10^{9} \mathrm{Pas}$. The measured till viscosity is an order of magnitude less. Thus the till beneath the Columbia Glacier does not significantly contribute to the drag at the bed of the glacier.

It should be emphasized that the reconstructed fully loaded curvature matches both the residual deformation (from which it was constructed) and also the degree of stem shortening $(18 \mathrm{~cm})$ needed to deform over whatever caused the gouges. Indeed, several parts of the above bending scenario have to match more than one observation, and in this sense the above is internally consistent. However, it is probable that many descriptions of the basal system are possible and self-consistent, despite the fact that the above mode of deformation and the implied stresses and strains (and strain rates) appear to match the observational data. In particular, if we relax the assumption that no unbending occurred, then a wide range of stress histories could be applied to the stem and lead to indistinguishable residual deformations. The above is the simplest model that fits the available data and is therefore offered as the most reasonable description.

Expected errors in the final determination of till strength depend largely on the bending scenario. However, even if the scenario is accepted, then the input data and the modeling need to be assessed for probable error and for sensitivity. The estimates of till strength rest mainly on the data on stem curvature in the region of the $65-\mathrm{cm}$ point and on the processing of this data by the elastoplastic model to produce a bending moment. The data on the stem deflection, although measured to an accuracy of $0.5 \%$, introduce what is essentially a discretization error since the deflections were measured with a resolution of 0.025 $\mathrm{cm}$. There are also measurement errors of the same order. This introduces considerable noise into the numerical calculation of the curvature (which is actually exaggerated by the high density of the data). Although large, this noise has the advantage of oscillating about the probable value and is effectively removed by averaging. The averaging process (described above) tends to reduce the peak curvature value and to estimate the possible importance of this, the raw data were analyzed in a $5-\mathrm{cm}$ region centered on the $65 \mathrm{~cm}$ point. The curvatures from the raw data are nowhere more than $20 \%$ of the averaged value and oscillate 
regularly above and below this value. Residual noise can be seen in Figure 5, but since the strength analysis rests on the fitted lines in the figure, the noise in the raw data is not important.

The data are processed by the elastoplastic model of equations (2) through (5) to produce Figure 5, and some estimate of the sensitivity of this modeling to -errors in the inputs and model parameters must be found. When there are no plastic strains, the model is purely elastic and therefore linear in its sensitivity. The difficulty is in estimating the sensitivity of the model in its nonlinear plastic response, where the bending moment is reduced with respect to the purely elastic case (the plastic yielding reduces the required bending stresses). Fortunately, it is possible to at least demonstrate the magnitude of the model's plastic response by comparison with the purely elastic case. As was pointed out above, the striations on the stem imply that it was dragged through the till at an angle of $30^{\circ}$ from the vertical. If the stem behaved purely elastically, this would have required a $600 \mathrm{Nm}$ bending moment. The plastically modeled result is a little more than half this moment. Thus in this specific application, the plastic response of the model is bounded (above) by the linear elastic response, and the change from plastic parameters of zero to the plastic parameters used in the model causes the output to change by a factor of 2 . Unless we are greatly in error in our modeling of the plastic response, the bending moment calculations are considerably more accurate than a factor of 2 , and the results appear to be no more sensitive to the plastic modeling, than to the elastic.

Previous work on the in situ strength of deforming till has yielded estimates that tend to be stiffer. Boulton and Hindmarsh [1987] in their study beneath the margin of the Breidamerkurjokull give results that imply viscosities over an order of magnitude greater than those derived here. Blake and Clarke [1989] report minimum viscosities a factor of 2 to 5 greater. It must be stressed that the measurements presented here are for the central region of a major valley glacier and actually represent the first in situ measurements under a large valley glacier. These measurements from Columbia Glacier are perhaps best compared with measurements made on Ice Stream B, Antarctica, which is also a large, fast moving ice mass. Kamb [1991] reports on tests of undisturbed basal till samples from beneath the central region of Ice Stream B, where it was found that yield strengths of the samples were similar to the plastic yield strength of the till in this study.

\section{CONCLUSIONS}

We interpret the penetrometry, turbidity, and sampling at the lower site to show that the ice at the lower site was underlain by a thin, 7-cm, veneer of basal debris overlying solid bedrock. Turbid water was flowing from the bed into an englacial system and supporting a column of fluidized debris that had been flushed into the drill hole by a basal water pressure somewhat higher than in the englacial system. This fluidization represents a mechanism for moving debris from the bed, into the ice, and thus represents an heretofore undemonstrated mechanism for the emplacement of rock debris or "erosion tools" into the ice. This mechanism requires either a temporary or continuous flow of water from the bed to an englacial system.

At the upper site the picture is less clear. The bed was covered by at least one half $\mathrm{m}$ of debris that showed signs of grinding and attrition. There was no evidence of water flow up the holes. The deformation of the drill stem has been shown to be compatible with a basal till layer at least $0.65 \mathrm{~m}$ thick

Striations on the stem imply that the till at the upper site is deforming and that the till near the ice moves with the ice speed, while the till nearer the bed moves more slowly. The striation density precludes the existence of a simple, narrow shear band at the ice/till interface, and suggests a constant shear rate with depth in the till. Further, the circumferentially banded locations of the striations imply that the subglacial till behaves as a plastic. A force calculation on the bent drill stem, assuming the till to be a plastic material, places the plastic yield strength of the till at less than 0.13 bar, with a best estimate of 0.055 bar. On the other hand, if the till is regarded as a viscous material, then the bending of the stem gives a measure of the effective viscosity of about $2 \times 10^{8} \mathrm{Pas}\left(2 \times 10^{9}\right.$ poise). Neither the calculated plastic yield strength nor the viscosity is able to support the $\sim 1$ bar basal shear stress of the glacier.

The upper and lower drill sites lie on a single ice flow line as determined from aerial photography. Point measurements of basal debris thickness should not be used as spatial averages. However, if the two basal debris thickness measurements were actually representative of the regions under the upper and lower sites, then the implied flux of debris under the sites can be estimated by the sliding rate and the debris thickness, assuming a linear velocity profile in the debris. The flux is of the order of $1 \times 10^{-5} \mathrm{~m}^{3} \mathrm{~s}^{-1}$ per meter of width for the upper site. This is more than 3 times the implied flux per meter width at the lower site. not including an additional correction for the narrowing of the glacier. The missing flux of debris could easily be carried by the subglacial hydraulic system of the Columbia Glacier which discharges highly turbid water at the snout.

The debris thickness difference between the two sites may indicate a different mode of basal sliding. Sliding may change from basal shearing in a debris layer, with high water pressure [Engelhardt et al., 1987], at the upper site, to high water pressure-induced cavitation and sliding over bedrock, with minor till, at the lower site. However, despite the difference in the-character of the bed at the two sites, it appears necessary that bedrock protuberances at both sites control the flow since it has been shown that the till at the upper site does not contribute significantly to the basal resistance.

\section{APPENDIX}

The derivation of (3) is sketched. We start by writing (1) in terms of a sum of moments over the cross section (increment of area $=d a$ ) of a bilateral-symmetric bending beam,

$$
M(z)=4 \int_{0}^{R} \sigma \eta d a
$$

where $\eta$ is distance in the beam transverse direction and $\sigma$ is the longitudinal stress in the beam at $\eta$. The radius of the beam is $R$. Equation (A1) sums the moments on over the crosssectional area of the beam. However, using the assumed ideal elastoplastic rheology of the stem, (A1) can be split into two parts, one for the elastic stresses $\left(\sigma_{e}\right)$ and the other for the plastic stresses $\left(\sigma_{p}\right)$,

$$
M=4 \int_{0}^{\zeta R} \sigma_{e} \eta d a+4 \int_{\zeta R}^{R} \sigma_{p} \eta d a
$$

where $\zeta$ is given by (4) in the text. For a thin-walled tube, the increment of area is 
A

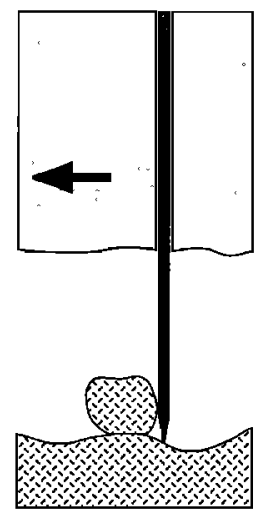

B

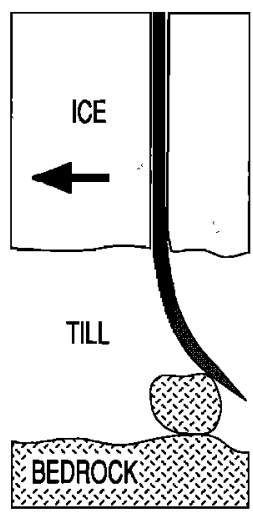

C

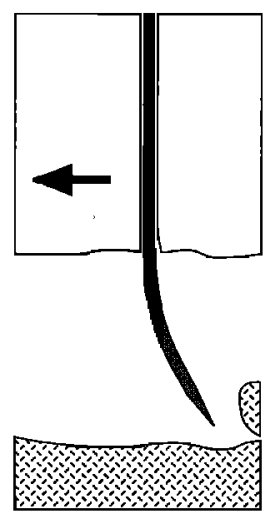

Fig. 7. The bending scenario: (a) The stem reaches bedrock after drilling through the ice and basal till. (b) The tip of the stem is advected into a boulder or bedrock protrusion $18 \mathrm{~cm}$ above the bed and starts to bend. (c) The stem bends, shortens by $18 \mathrm{~cm}$, and slides over the obstruction. In its bent state it is dragged through the basal till for 5 days.

$$
d a=\frac{t}{\left(1-\frac{\eta^{2}}{R^{2}}\right)^{1 / 2}} d \eta
$$

where $t$ is the tube thickness. The elastic and plastic stresses are given by.

$$
\sigma_{e}=E \eta y^{\prime \prime} \quad, \quad \sigma_{p}=Y+W(\eta-\zeta R) y^{\prime \prime} .
$$

Equations (A3) and (A4) are substituted into (A2), and the result is integrated in the radial direction. Equation (4) in the text is used to eliminate $Y$ from the second integrand. The result is an algebraic expression for $M(z)$ in terms of the curvature of the stem $y^{\prime \prime}$ and in terms of the stem parameters $E, W$, and $Y$ (parameterized using $\zeta$ ). This result is the expression for $M(z)$ in equation (3) in the text.

Acknowledgments. The authors would like to acknowledge thorough reviews by $\mathrm{J}$. Walder and an anonymous reviewer. This study was supported by NSF grant DPP8619352.

\section{REFERENCES}

Alley, R.B., Water-pressure coupling of sliding and bed deformation, II, Velocity depth profiles, J. Glaciol., 35, 119-129, 1989.

Blake, E.W., and G.K.C. Clarke, In situ bed strain measurements

beneath a surge-type glacier (abstract), Eos Trans. AGU, 70, 1084, 1989.

Blake, E.W., G.K.C. Clarke, and M.C. Gerin, Tools for examining subglacial bed deformation, J. Glaciol., in press, 1992.

Boulton G.A., and R.C.A. Hindmarsh, Sediment deformation beneath glaciers: Rheology and geological consequences, J. Geophys. Res., 92, 9059-9082, 1987.

Byars E.F., and R.D. Snyder, Engineering Mechanics of Deformable Bodies, 2nd. ed., p. 444, International Textbooks, Scranton, Pa., 1969.

Engelhardt H., M. Fahnestock, N. Humphrey, B. Kamb, and M. Meier, Rapid basal sliding in a large tidewater glacier caused by high basal water pressure (abstract), Eos Trans. AGU, 68, 1272, 1987.

Engelhardt H., N. Humphrey, and B. Kamb, Borehole geophysical observations on Ice Stream B, Antarctica (abstract), Eos Trans. AGU, $71,1302,1990 \mathrm{a}$.

Engelhardt H., N. Humphrey, B. Kamb, and M. Fahnestock, Physical conditions at the base of a fast moving Antarctic ice stream, Science, 248, 247-249, 1990 b.

Fahnestock M., The influence of water on basal sliding velocityInterpretation of data from Variegated and Columbia glaciers, Alaska (abstract), Eos Trans. AGU, 71, 1315, 1990.

Hill, R., The Mathematical Theory of Plasticity, 2nd ed., p. 356, Clarendon, Oxford, 1956.

Humphrey, N.F., and K.J. Echelmeyer, Hot-water drilling and borehole closure in cold ice, J. Glaciol., 36, 287-298, 1990.

Kamb, B., Rheological nonlinearity and flow instability in the deforming bed mechanism of Ice Stream motion, J. Geophys. Res., 96, 585-595, 1991.

Krimmel, R.M., Columbia Glacier in 1986: 800 meter retreat, U.S. Geol. Surv. Open File Rep., 87-207, p. 7, 1987.

Meier M.F., S. Lundstrom, D.B. Stone, R.M. Krimmel, R.A. Walters, W.W. Dunlap, and B. Kamb, Relation between water input and sliding rate of Columbia glacier, Alaska (abstract), Eos Trans. AGU, 68, $1272,1987$.

Middleton, G.V., and J.B. Southard, Mechanics of sediment movement, Soc. Econ. Paleontol. Mineral., Short Course, 3, 1977,

Murphy, G., Properties of Engineering Materials, 2nd ed., p. 459, International Textbooks, Scranton $\mathrm{Pa}, 1947$.

Van Dyke, M., Perturbation Methods in Fluid Mechanics, p. 271, Parabolic, Stanford, Calif., 1975.

Walters, R.A., Small-amplitude, short-period variations in the speed of a tide-water glacier in south-central Alaska, U.S.A., Ann. Glaciol. 12, 187-191, 1989.

H. Engelhardt, M. Fahnestock, and B. Kamb, Division of Geological and Planetary Sciences, California Institute of Technology, Pasadena, CA 91125.

N.F. Humphrey, Department of Geology and Geophysics, University of Wyoming, Laramie, WY 82071.

(Received May 17, 1991; revised August 3, 1992; accepted August 6, 1992.) 